\title{
ADICIONES AL TEMA DE LAS CITAS CERVANTINAS EN CALDERÓN: LAS CITAS SOBRE LOPE DE VEGA*
}

En un anterior trabajo ${ }^{1}$ hablamos de la admiración del dramaturgo madrileño por el autor del Quijote al estudiar pasajes de sus comedias donde hay alusiones a Cervantes y, más en concreto, a algunas de sus novelas. El sentido cómico de tales versos por el contexto puede sugerir que la comedia perdida Don Quijote de la Mancha tendría tal tono, como sugiere Edward M. Wilson, si bien al faltarnos el texto nos priva de sorpresas posibles que suelen encontrarse al leer despacio el teatro de la época barroca. Pues es innegable que el mismo Calderón en los enredos dramáticos se apoya en el sentido equívoco de los versos, de la palabra, cuyo contexto parece buscar a veces la imagen de un péndulo de reloj para ofrecer un sentido polisémico de los signos lingüísticos.

\section{EL PERSONAJE ENQUIJOTADO DE LA COMEDIA BASTA CALLAR}

Vamos a considerar cómo fluctúa en las figuras de su teatro el papel de tal caballero y el léxico que le caracteriza. Y elegimos como

* En este IX-CIAC el prof. Ignacio Arellano leyó una ponencia titulada «Cervantes en Calderón», cuyo contenido metodológico es distinto y más amplio a mi línea de trabajo. Agradezco, por otro lado, las notas que sobre Lupus in fabula me envió posteriormente el prof. Arellano, algunas de ellas aprovechadas por mí en su lugar y a quien agradezco su gesto, pues el tema de lupus y fabula lingüísticamente es muy amplio y es imposible abarcarlo en esta comunicación.

1 Nos referimos a la comunicación «Enquijotóse mi amo o el tema del caballero idealista en las comedias de Calderón", en Actas del tercer Congreso internacional de Cervantistas (III-CINDAC). Editor ANTONIO BERNAT VISTARINI, Palma. Universitat de les Illes Balears. 1998, pp. 619-629. 
corolario del trabajo anterior Basta callar, reelaborada por Calderón hacia 1652 y situada en una región histórica gala, el Bearne.

En la segunda jornada el gracioso Capricho, criado de D. César (se casará al final con D. ${ }^{a}$ Serafina), aparece en el escenario de la plaza donde está el palacio ducal de Bearne, en uno de cuyos balcones están Serafina y su criada Estela; en otro están Margarita de Fox (hermana del Duque) con la dama Flora, mientras en el terrero están, inadvertidos por las damas, Federico, conde de Mompeller, acompañado de Fabio y Libio, personal a su servicio. Las canciones desde los balcones se entrelazan, hasta que es advertida la presencia de Capricho y se origina un nuevo clima en la escena de la espera amorosa. Pues tanto Serafina como Margarita anhelan al galán Ludovico, el mismo D. César que Calderón ha explicado según su afición lingüística a comentar léxico sus personajes (en las comedias y autos):

\begin{abstract}
MARgarita. ¡Ah, sí! Ya no me acordaba / ¿Criado de César no eres? / CAPRICHO. César mi dueño se llama, que es lo mismo que llamarse / una negra Mari-Blanca. / MARGarita._¿Cómo? CAPRICHO.-Como «César» dice / victorias, triunfos y palmas; / y él toda su vida ha sido / desdichas, penas y ansias. / Aunque digo mal, pues desde / que, sin estar enojada / ni haberte reconciliado / con él, le volviste el habla, / todo es dichas y venturas. / FLORA.- No tu buen humor se valga, / para jugar del vocablo, / de equívocos; que no falta / quien diga que no es su nombre / César. / CAPRICHO.-Diránlo las malas / lenguas, porque antes de ahora / Ludovico se llamaba; / pero heredó un mayorazgo, / que le obliga a nombre y armas / de César ${ }^{2}$.
\end{abstract}

Al principio de esta escena del encuentro de Capricho con Flora y Margarita, Calderón pone en juego la confusión de identidad del criado y su identificación con la palabra andante:

Flora.- ¿Cómo aquí, / hidalgo, movéis las plantas?/ [...] / MARGARITA.No te turbes, alza. / ¿Quién eres? CAPRICHO.-Un escudero / andante antes que llegara / aquí; pero ya parante lo soy ${ }^{3}$.

Hasta encontramos en esta comedia de un Calderón clásico (retoca para perfeccionar una obra anterior) un esbozo, en boca de doña Margarita, de las clases posibles de ficciones que se conocen del riesgo que asume el caballero por la dama que le subyuga. Así

2 Jornada 1. ${ }^{\text {a }}$, p. 1713 de la edición de Á. VAlbuena BRIOnEs. Madrid. Obras Completas, tomo II. Comedias. 1973. Folio 500 de la Verdadera Quinta Parte de Comedias (Madrid, 1682), vol. XIV de Comedias de CALDERÓN. A facsimile edition prepared by D. W. CRUICKSHANK and J. E. VAREY. Tamesis Books Limited, 1973: Assí por ¡Ah, sí!

3 Jornada $1 .^{\mathrm{a}}$, p. 1713 de Obras completas, Folio 500 de Verdadera Quinta Parte de Comedias. 
se tiene por archiconocido (ya se ha visto) que la favorezca en acasos ('sucesos imprevisibles') de la caza y en trances de una batalla. Viene luego lo que cuentan las fábulas e historias varias: que la ampare ante los peligros del fuego, del agua, del monstruo que la embiste y del bruto que la arrastra (el caballo). Y lo más nuevo (no ha mucho dice el verso) es socorrer a una hermosura que cae por una ventana en novela o farsa ${ }^{4}$.

Y volvamos a la presencia ya advertida de Capricho en la plaza, quien trae una disculpa fingida de su señor. Se enoja Serafina al descubrir que no es el caballero deseado y cierra su ventana con Estela. También Margarita se irrita por lo mismo y manda a Flora así:

MARgarita.-Deja, Flora, aquesa reja, / y para locos los deja a él y su $\mathrm{amo}^{5}$.

Entonces el conde Federico, que pretende a Margarita de Fox y por ello ronda la plaza, decide intervenir sin conocer quién es el personaje que ha alterado la escena, y sobrevienen los versos con el recuerdo cervantino citados en nuestro trabajo ${ }^{6}$. Se marcha luego el Conde tras el reto a Capricho (a quien cree hidalgo) con sus acompañantes, mientras que para el gracioso todo ha sido un ardid para ganar tiempo. Y tan a gusto se encuentra en su papel, que al llegar el Duque de Bearne, D. Enrique de Fox, acompañado de D. Carlos y nada menos que de su señor, D. César (que le reconoce de inmediato), califica de majadero, de otros acompañado, al Conde con quien se ha desafiado de mentirijillas, claro. Y su señor quitará tensión a la escena al advertir por dos veces al Duque que se trata de un loco, palabra que luego comentaremos en otra comedia.

Mas Calderón ya nos ha mostrado anteriormente el grado de confianza entre amo y criado:

CÉSAR.-Serafina... ¡Ay! Que al nombrarla, / cada sílaba del nombre / es un pedazo del alma. / Serafina, otra vez digo, / y otra vez el pecho arranca / mitades del corazón. / [...] / tú / puedes ir, Capricho, a casa. / Alguna ropa prevén, / y con dos postas me aguardas. / Capricho.-¿Qué dices? CÉSAR.-Lo que ha de ser. CAPRICHO.- ¿Con qué, señores, se paga / el gustazo de servir / a un loco? CÉSAR.-Pues di, ¿qué extrañas? / CAPRICHO.-Verte anteayer desterrado, / ayer muerto, hoy en privanza, / y no saber a estas horas / en qué te he de ver mañana. / CÉSAR.-Verásme ausentar, haciendo / por la más bella tirana / que vio Amor en sus impe-

\footnotetext{
4 Jornada 1. ${ }^{\text {a }}$, p. 1712 de Obras completas. Folio 499 de Verdadera Quinta Parte de Comedias.

5 Jornada 2.a, p. 1732. Fol. 525 de Verdadera Quinta Parte de Comedias.

6 Véase pp. 625-26, de Obras completas, correspondiente al folio 525 y siguiente de Verdadera Quinta Parte de Comedias.
} 
rios, / la fineza de no darla / el pesar de verme vivo. / Mas, jay de mí! que no basta / apartar della la vida, / si apartar no puedo el alma. (Vanse) ${ }^{7}$.

Junto a la muestra de las relaciones en privado entre señor y criado, Calderón, como artista del Barroco y en esta misma comedia, nos escribe este pasaje entre los caballeros D. César y D. Carlos (y Capricho):

CARLOS.-Que salieras esperaba / deste jardín a la puerta./ Capricho.-Ya prevenidas están / las postas y las maletas. / CÉSAR.-Pues para que de una vez / se empiecen ambas respuestas, / ve tú y las postas despide. / y vos inferid de aquesta / novedad ... D. CARLOS.—¿Qué? César.- Que ya hay otra / que añadir a la novela. / D. CARLos.-De gusto debe de ser, / según el semblante muestra ${ }^{8}$.

\section{MUDANZA Y LOCURA}

La mudanza, según dicen los personajes calderonianos, de cualidades entre el caballero y su criado es frecuente en las comedias y lo suele expresar el gracioso como explicación o llamada de atención al público (lector o espectador) sobre su nueva situación anímica. En la plaza ambientada en Madrid No hay burlas con el amor el autor nos ofrece un pasaje nítido de la mudanza de sentimientos entre el criado Moscatel y su señor D. Alonso de Luna:

D. Alonso.-_Válgate el diablo! ¿Qué tienes, / que andas todos estos días / con mil necias fantasías? / Ni a tiempo a servirme vienes, / ni a propósito respondes; y por errarlo dos veces, / si no te llamo, pareces, / y si te llamo, te escondes. / ¿Qué es esto? Dilo. Moscatel.-iAy de mí! / Suspiros que el alma debe . / D. Alonso.-Pues ¿un pícaro se atreve / a suspirar hoy así? / Moscatel.-Los pícaros, ¿no tenemos / alma? D. ALONSO.Sí, para sentir, / y con rudeza decir / de su pena los extremos; / mas no para suspirar; / que suspirar es acción / digna de noble pasión. / MosCATEL.—¿Y quién me puede quitar / la noble pasión a mí? / D. ALONSO.¡Qué locuras! Moscatel.—¿Hay, señor, / más noble pasión que amor? / D. Alonso.- Pudiera decir que sí; / mas para ahorrar la cuestión, / que no, digo. Moscatel.- ¿Que no? Luego / si yo a tener amor llego, / noble será mi pasión. / D. ALONSO.—¿Tú amor? Moscatel.-Yo amor. D. Alonso.-Bien podía, / si aquí tu locura empieza, / reírme hoy de tu tristeza / más que ayer de tu alegría. / MosCATEL.-Como tú nunca has sabido / qué es estar enamorado; / como siempre has estimado / la libertad que has tenido, / tanto que en los dulces nombres / de amor fueron tus placeres / burlarte de las mujeres / y reírte de los hombres, / de mí te ríes, que estoy / de veras enamorado. / D. Alonso.-Pues yo no quiero criado / tan

7 Jornada 1. ${ }^{\text {a }}$, pp. 1716-17 de Obras completas. Folios 506-507 de Verdadera Quinta Parte de Comedias.

8 Jornada 2. ${ }^{\mathrm{a}}$, p. 1723 de Obras completas. Folios 513-14 de Verdadera Quinta Parte de Comedias. 
afectuoso. Hoy / de casa te has de ir. Moscatel.-Advierte ... / D. ALONSO._¿Qué querrás decir? / Moscatel.-Que se ha trocado la suerte / al paso, pues siempre dio / el teatro enamorado / el amo, libre el criado. / No tengo la culpa yo / desta mudanza ; y así / deja que hoy el mundo vea / esta novedad, y sea / yo el galán, tú el libre?.

D. Alonso despide enfadado a su criado, a quien de nuevo considera pícaro cuando llega D. Juan de Mendoza, le pregunta qué está ocurriendo e informado por D. Alonso, le defiende con esta argumentación:

D. JUAN.-Amor es quien da valor / y hace al hombre liberal, / cuerdo y galán.

Y vendrá la respuesta de la ficción dentro de la escena:

D. Alonso: ¡Pesia tal! / De los milagros del amor / la comedia me habéis hecho, / que fue un engaño culpable, / pues nadie hizo miserable, / de avaro y cobarde pecho / al hombre, sino el amor ${ }^{10}$.

En otros pasajes la mudanza no está ligada directamente al amor, aunque está próximo al caballero enquijotado; así en la comedia El escondido y la tapada, muy posiblemente anterior a Basta callar, el diálogo entre D. César y su lacayo Mosquito registra nada menos que estos tres adjetivos: Caballero parante / caballero andante (en oposición) y como contraste, Calderón lleva la parodia de la mudanza hasta caballero escondido:

Mosouito.-[...] / Pero dime: qué papel / me toca en esta comedia / del caballero escondido? / D. CÉSAR.-Pues no estás culpado, fuera / te quedarás a avisarme / de todo lo que suceda ${ }^{11}$.

Esta locura por el amor ${ }^{12}$ es distinta a la que la dama Laura define en Manos blancas no ofenden:

SERAFINA.-Detente, Celia [a César, que empuña una espada varonilmente, pero disfrazado de mujer]. / CÉSAR.-Es en vano detenerme. / No soy Celia; César soy,/ ya que tú que lo sea quieres./ SERAFina.-Mira, Celia, que no hay / ninguno ahora presente, / con quien sea menester / que el pasado enojo esfuerces. / CÉSAR.-Una vez en este traje, / perdonadme; que no puede / volverse atrás mi valor. / LAURA.-Ella lo que finge cree. / FEDERI-

9 Jornada $1 .^{\text {a }}$, pp. 187-191 del texto de la edición, estudio y notas de IGNACIO AREllano. Pamplona, Ediciones Universidad de Navarra. 1981.

10 Jornada 1.a, pp. 192-93.

11 Jornada $1 .^{\text {a }}$, p. 678 de Obras completas. Folio 523 de Septima Parte de Comedias (Madrid. 1683).

12 Locura. Insania, dementia, etc. Loquear, hazer locuras o burlarse y holgarse descompuestamente. (Tesoro de la Lengua Castellana o Española de SEBASTí́N DE Covarrubias. Madrid, Ediciones Turner). 
CO.-Tal género de locura / ha sucedido mil veces. / CÉSAR.-No embarecéis que una vida / quite a un traidor, a un aleve. / LAURA.-Mira, Celia, que es locura creer lo que finges eres. / FEDERICo.-Dejadla; que ya enseñado estoy que damas me afrenten, / y a hacer dello gala ${ }^{13}$.

En esta comedia ya señalamos las citas de la andante caballería y Don Quijote de la Mancha, sin faltar tampoco otro elemento léxico del mismo campo lingüístico, novela:

FEDERICO [Aparte].- ¡No sea sino mal venido! / Quien en el mundo creyera / sino echándose a pensar / imaginadas novelas, / que desde Alemania el padre / de Lisarda al Po viniera / a embarazarme el decir, / ¡ay infelice!, que es ella / la que en César disfrazada, / celosa vengarse intenta / de mí [...] ${ }^{14}$.

CÉSAR.-Si algún ingenio quisiere / escribir una novela, / ¿podrá inventarla fingida / mayor que en mí se halla cierta? ${ }^{15}$.

Sucede además que estas presencias léxicas aparecen en comedias con citas de libros de caballerías, como en la pieza refundida Peor está que estaba, cuya primera versión lleva la firma de Luis Álvarez, y donde se encuentra un Gobernador de Gaeta, quien a interrogar al gracioso Camacho, criado de D. César Urbino, oye de nuevo la tópica contestación de Soy un escudero / deste caballero andante ${ }^{16}$. Y en un diálogo en la jornada siguiente se halla el recuerdo de tales libros con el remedo lingüístico del género:

[Habitación en una torre]. (Salen Camacho y Don César).

CAMACHO.- ¡Buenos hemos quedado! / CÉSAR.-¿Veslo? Pues todo es bien empleado, / a trueco de haber visto / aquel rostro que vi. CAMACHO.- iCuerpo de Cristo / contigo, y con su rostro! / Valiera tanto más que fuera un mostro, / y que a un lado tuviera / otro con barbas; aunque yo le viera / y no estuvieras preso, / que haber visto perfecto con exceso / un ángel con malicia / pues él nos ha entregado a la justicia. / CÉSAR.—¿Tal dices? CAMACHO.—¿Qué te espanta, / si ya se vive con malicia tanta? / Y la primera vez no vino acaso / sino a espiarnos; porque fuera paso / de caballero andante, / entrar las dos asaz de mal talante, / huyendo de algún fiero / malandrín, demandando al caballero / la mampare en su cinta, / maguer que fuese noble. Quita, quita / esto del pensamiento; / que es lástima sacar aqueste cuento / de una selva encantada, / donde fabló la infanta mesurada / mil famosos requiebros / a Esplandián, Belianis y Beltenebros ${ }^{17}$.

13 Jornada 3. a, p. 1123 de Obras Completas. Folio 101 de Octava Partede Comedias (Madrid, 1684): perdóname por perdonadme.

14 Jornada 2. ${ }^{a}$, p. 1102 de Obras Completas. Folio 75 de Octava Partede Comedias.

15 Jornada 2. ${ }^{\text {a }}$, p. 1104 de Obras Completas. Folio 77 de Octava Partede Comedias.

16 Jornada 1.a, p. 323 de Obras Completas. Folio 403 de Primera Parte de Comedias (Madrid, '1640'); fol. 229 v. de Primera Parte (Madrid, 1640); fol. 229 v. (Madrid, 1636) de Primera Parte.

17 Jornada 2. ${ }^{\text {, }}$, p. 329 de Obras Completas. Folio 233 v. y 234 r. de Primera Parte de Comedias: monstruo por mostro; ella no vino acaso / la vez primera, sino a espiarnos / porque fuera paso por " Y la primera vez no vino acaso / sino a espiarnos; porque fuera paso" (Madrid, 1636). Ídem en Madrid 1640 y folios 410-11 de Madrid, '1640'. 
Hace ya años que Ángel Valbuena Briones comentó:

«Es evidente para el lector asiduo de Calderón el mundo caballeresco en el que se desenvuelven sus personajes. La actitud heroica, la defensa de la virtud, el sentimiento del honor son rasgos que se repiten en la fronda literaria del insigne dramaturgo" ${ }^{18}$.

En el mismo estudio recuerda el plano cómico de los criados, lacayos o graciosos, cuya presencia tan importante es para este estilo de comedias, con su repercusión lingüística.

\section{LAS CITAS SOBRE LOPE DE VEGA EN CALDERÓN}

$\mathrm{Al}$ ir estudiando las comedias, hemos ya manifestado que otros autores conocidos y obras leídas por D. Pedro aparecen en sus versos elogiadas. Creemos que se debe interpretar como muestra de sentirse integrado en una tradición literaria cuyo vínculo común es la lengua literaria ${ }^{19}$. Y entre los nombres y títulos nos ha llamado la atención las citas sobre Vega Carpio, que podemos clasificar en tres apartados:

1) Citas o alusiones normales.

Son dos las encontradas: Los melindres de Belisa y El perro del hortelano.

En la comedia No hay burlas con el amor el caballero D. Juan de Mendoza le cuenta la pena mía, / del amor (versos 100-101), pues una dama, doña Beatriz Enríquez, hija de un amigo de su padre, D. Pedro Enríquez, le ha alterado su mente:

\footnotetext{
«Beatriz, de Leonor hermana, / es el más raro sujeto / que vio Madrid, porque en él, / siendo bellísima y siendo / entendida, están echados / a perder, por los extremos / de una extraña condición / belleza y entendimiento" (versos 207-214).
}

Tanto terremoto espiritual en D. Juan proviene de dos cualidades de D. ${ }^{a}$ Beatriz; una al parecer poco frecuente en la época:

«De su ingenio es tan amante, / que por galantear su ingenio , / estudió latinidad / y hizo castellanos versos. / Tan afectada en vestirse, / que en todos los usos nuevos / entra, y de ninguno sale» (221-227).

18 Hacia Calderón. Quinto Coloquio Anglogermano. Oxford. 1978 [1982], pp. 18. El título es «Los libros de caballerías en el teatro de Calderón».

19 Si se supone que Calderón cita a los más sobresalientes autores y títulos leídos, es razonable suponer que no debió conocer el Libro de Buen Amor; suposición que puede concordar con la historia de los códices, y cuya primera publicación parcial se debe a TOMÁs ANTONIO SÁNCHEZ (1790). El sentido jocoso, a veces trágico, de Juan Ruiz creemos que hubiera hecho las delicias de Calderón. 
Y prosigue el texto (Calderón juega con las palabras como si se tratara de un péndulo en movimiento, visualizado en un contexto de espejos que lo reflejan; así los versos ocultan el pensamiento del autor, que como gran estilista de la lengua, juega con el arte hablado):

«Cada día por lo menos, / se riza dos o tres veces, / y ninguna a su contento. / Los melindres de Belisa, / que fingió con tanto acierto / Lope de Vega, con ella / son melindres muy pequeños; / [... ${ }^{20}$.

La segunda cita está puesta en boca del lacayo Meco al responder a la dama Aurora, que ha salido a escena tapada junto a su criada Laura:

«D. ${ }^{a}$ AURORA.—¿Vendrá muy tarde? / MECo.-Como una dama quisiere, / por quien vive y por quien muere, / por quien yela y por quien arde. / Su hermosura adora en vano, / quedando en su voluntad / aquella civili$\mathrm{dad} /$ del perro del hortelano; / [... $]^{21}$

2) «En mi pena se infiere / que el que piensa que no quiere, / el ser querido le engaña».

Los versos anteriores, exclamados por D. Juan de Mendoza en No hay cosa como callar ${ }^{22}$ y señalando al Fénix de España como autor, son reiterados en ¿Cuál es mayor perfección? por Inés, criada de doña Leonor, a D. Luis de Mendoza:

INÉS.-De un adagillo que a España / añadió Lope, se infiere.../ D. LUIS.¿Qué? INÉs.-Quien piensa que no quiere / el ser querido le engaña ${ }^{23}$.

Es un caso de admiración, a tono con la grandeza que de Lope de Vega debía tener Calderón, a pesar de posibles roces, inevitables a veces cuando dos personas del mismo oficio coinciden en la vida ${ }^{24}$.

20 Jornada 1. ${ }^{\text {a }}$, pp. 196-200 de la edición de ARELLANO.

21 Jornada 2. a, p. 367 de Obras completas. Folio 474 de Verdadera Quinta Parte de Comedias.

22 Jornada 3. a, p. 1029 de Obras completas. Folio 249 de Séptima Parte de Comedias.

${ }^{23}$ Jornada 3. ${ }^{\text {, }}$, p. 1651 de Obras completas. Folio 285 de Verdadera Quinta Parte de Comedias.

24 Consúltese de Luis IgLESIAS FEIJOo «Que hay mujeres tramoyeras»: la «Matemática perfecta" de la comedia calderoniana» en La comedia de enredo. Actas de las XX Jornadas de teatro clásico. Almagro, julio de 1997. Edición cuidada por Felipe B. Pedraza y Rafael González Cañal. Murcia, 1998, pp. 201-236. Luis Iglesias sigue a JUAN MANUEL RozAS en sus Estudios sobre Lope de Vega. Madrid, Cátedra. 1990. Sin embargo creo que, a pesar de la posibilidad de que Calderón pueda ser uno de los "pájaros nuevos" aludidos en Amarilis y demás, D. Pedro no olvidó expresar su admiración por quién era su modelo al haber compuesto el Arte nuevo de hacer comedias. Todos sabemos que aquél, por paradojas de la vida, tuvo 
Según escribió Cotarelo y Mori, se conserva un manuscrito autógrafo de Lope de la comedia ¡Ay, verdades, que en amor...! ${ }^{25}$, pieza al parecer creada de un romance impreso como anónimo en la Primavera y flor de los mejores romances ... de varios Poetas, del Licenciado Pedro Arias (Madrid. 1621), que luego el comediógrafo demostró su autoría. Dada la belleza lírica, reproducimos el romance según el texto de D. Emilio:

«iAy, verdades, que en amor / siempre fuistes desdichadas! / ¡Buen ejemplo son las mías, / pues con mentiras se pagan! / Cuando traté con engaños / tu verdad, Filis ingrata, / iqué de quejas vi en tus ojos; / qué de perlas vi en tu cara! / ¡Oh, qué de veces te dije, / cuando a mi puerta llamabas: / -En vano llama a la puerta / quien al corazón no llama!_ / Mis pastores te decían: / - No está Fabio en la cabaña. - / Y estaba diciendo yo: / ¿Para qué busca quien cansa? / A tus quejas solamente / daban respuesta las aguas; / porque murmuraban, Filis, / que no porque te escuchaban. / Acuérdome que una noche / me dijiste, con mil ansias: / -Déjate, Fabio, querer, / pues no te cuesta nada. / No quiero yo que me quieras; / que, como amor es el alma, / nunca vi mujer discreta / que bien quisiese forzada.- / En el umbral de tu puerta / reñíamos hasta el alba: / tú, porque había de entrar; / yo, por no entrar en tu casa. / -Castiguen, Fabio, los Cielos / dijiste desesperada- / el fuego con que hielas / y el hielo con que me abrasas. - / Porfiaste, hermosa Filis; / todo el porfiar lo acaba; / que quien piensa que no quiere / el ser querido le engaña. / En el trato ni en el tiempo / nadie tenga confianza; / que se pasan sin sentir, / y se sienten cuando pasan. / Tanto te vine a querer, / que juntos nos envidiaban: / la luna, al bajar la noche; / el sol, al salir el alba. / Los prados, montes y selvas / de vernos se enamoraban; / verdes lazos aprehendían / las yedras enamoradas. / Mas bajando en este tiempo / de las heladas montañas / Silvio, tu antiguo pastor,/ trajo de allá tu mudanza. / No perdiste la ocasión; / pues cuando yo te adoraba, / de mis pasados desdenes / quisiste tomar venganza. / Filis, ya muero por ti; / confieso que se me pasan / en tus umbrales las noches, / los días a tus ventanas. / No llamo porque imagino / que has de responder airada: / — ¿Para qué llama a la puerta / quien al corazón no llama?»- / Si finjo que no te quiero, / es invención de quien ama; / que, cuando tú no me miras, / hago espejo de tu cara. / Prendas que tú dabas, Filis, / y de que yo me enfadaba, / agora las visto y pongo sobre los ojos y el alma. / No te encarezco mis penas / por no dar gloria a la causa: / hasta que yo las padezca, / sin que tú tomes venganza. / No quieras más de que son / las locuras de amor tantas, / que vengo a poner la boca / adonde los pies estampas. / Mas, con todo lo que digo, / no pienso hablarte palabra; / que en celos que se averiguan / las amistades se acaban» ${ }^{25}$.

sus problemas con otros personajes, dos de ellos de la Iglesia, aparte del grave incidente juvenil del convento de las Trinitarias, que sí fue sonado.

Para los elogios de Lope y Juan Pérez de Montalbán (El laurel de Apolo, 1630, y Para todos. Exemplos morales, humanos y divinos,..., 1632), léase el prólogo de VAlbuena BRIOnes a Comedias de capa y espada II en Clásicos Castellanos, n. ${ }^{\circ} 137$. Madrid, Espasa Calpe. 1962.

25 Tomo III de las Obras de Lope de Vega publicadas por la Real Academia Española (Nueva edición). Obras dramáticas. Prólogo de EMILIO COTARELO Y MORI. Madrid, 1917, pp. XXII-XXIII; las de la edición de la comedia 502-534. 
Cotarelo comenta tras el romance:

«Este es el resumen y moraleja de la comedia: desdeñar favorecido y amar desdeñado» ${ }^{26}$.

3) Lupus in fabula.

Calderón, en un pasaje de su comedia Peor está que estaba, escribe unos versos recitados por el gracioso Camacho donde aparece el dicho en latín, con una atribución a Lope, que gracias al TESO hemos podido comprobar, y luego esclarecer la diferencia lingüística en un texto ciceroniano. Los versos del dramaturgo barroco son los siguientes:

CAMACHO.-[...]. Mas por lo que hemos dicho / de aquella dama andante del capricho / singular, ella viene; / y aquí lugar acomodado tiene / lo de «lupus in fabula», que quiere / decir (según colijo) / que así Lope a sus fámulos lo dijo ${ }^{27}$.

Hay dos textos latinos con el dicho, uno en un contexto escueto perteneciente a la comedia Adelfos de Terencio (acto 4. ${ }^{\circ}, 1 .^{\mathrm{a}}$ ), y otro de Cicerón, que transcribimos:

"De Varrone loquebamur: lupus in fabula. Venit enim ad me et quidem id temporis, ut retinendus esset. Sed ego ita egi, ut non scinderem paenulam. Memini enim tuum: "et multi erant nosque imparati». Quid refert? Paulo post C. Capito cum T. Carrinate. Horum vix attigi paenulam. Tamen remanserunt. Cecidi belle» (Att. 13. 33 a. 1).

Tal como lo toma Calderón (Vega Carpio cita en romance con variantes, como veremos), es válida la definición de Herrero Llorente:

«3870 - Lupus in fabula. El lobo está en la fábula. Se dice de la persona que aparece justamente cuando se está hablando de ella» ${ }^{28}$.

Mas si el texto ciceroniano se lee con más amplitud, el sentido es más bien lo inoportuno que resulta quien(es) se presenta(n) sin

Hay en curso de publicación una imprescindible colección de todas las comedias de Lope por el «Proyecto de edición de las obras dramáticas de Lope de Vega» (PROLOPE) a cargo de un equipo de filólogos dirigidos por ALBERTO BLECUA y Guillermo SERes (Dpto. de Filologia Espanyola de la UAB).

26 En la página XXIII.

27 Jornada $1 .^{\text {a }}$, p. 321 de Obras completas, II. Folio 228 r. de la Primera Parte de Comedias de Calderón (Madrid, 1636 y Madrid, 1640; folio 400 de Madrid, 1640). El Teatro Español del Siglo de Oro (TESO) está publicado por Chadwyck-Healey España, S.L.

28 Herrero Llorente, Víctor José, Diccionario de expresiones y frases latinas. Madrid, Gredos, $1985^{2}$. 
previo aviso y más cuando incomodan con su presencia, «como el lobo que cae sobre el rebaño justamente a la hora de la siesta, que es sagrada» ${ }^{29}$.

En cuanto a la lexía textual latina, el lexema lupus procede onomasiológicamente de lupus est homo homini (Plauto, Asin. 495), con el sema de lo imprevisto causado por una presencia que desconcierta por la amenaza (cuando se une a fábula para formar la frase). Precisamente por el otro lexema, fabula, se puede rastrear en la tradición clásica del género fabulesco otro parentesco léxicosemántico del hombre y el lobo a través de la presencia inesperada del lupus, donde aparecen los semas de peligrosidad y sobresalto, sin personalizar al canis lupus. En este otro campo léxico puede relacionarse con el tema tratado de la fábula del pastor bromista, también titulada el pastor que bromeaba ${ }^{30}$.

Y sin olvidar que los clásicos de la Literatura romance bebían de los maestros anteriores, mientras Calderón, más intelectual, prefiere la cita en latín, Lope llega a romancearla con variantes hasta en seis comedias («así Lope a sus fámulos lo dijo»; después comentaremos fámulos). He aquí los textos:

De la comedia El ruiseñor de Sevilla:

FABIO.- ¿Paréceos bien? PADRE.-Tratadlo, por mi vida, / como que vos lo hacéis; y si gustare, / a casa me venid a dar las nuevas. / FABIO.-El lobo está en la fábula. PADRE.-Yo espero. (Salen don Juan y Fineo) ${ }^{31}$

De El Argel fingido y renegado de amor:

ROSARDO.-Y más que viene aquella fiera ingrata, / mi primera verdad y pensamiento / y el dulce basilisco que me mata. PIALí.-Escucha, pues, que el lobo está en el cuento. (Sale Flérida) ${ }^{32}$.

De Roma abrasada:

NERÓN.-Oye; el lobo está en el cuento. (Sale Otón) ${ }^{33}$.

29 Agradezco a mi colega LoIs C. PÉREz CASTRo (CSIC) su inestimable colaboración para interpretar los textos latinos.

30 Consúltese Historia de la fábula greco-latina de FRANCISCO RoDRíGUEZ ADRADOS. Madrid, Editorial de la Universidad Complutense. 3 tomos (1979, 1985 y 1987), así como Fábulas de Esopo. Vida de Esopo. Fábulas de Babrio. Traducción y notas de P. BádENAS DE LA PEÑa y J. LóPEZ FACAL. Madrid, Editorial Gredos. 1978. También agradezco la colaboración de mi colega JUAN RODRÍGUEZ SOMOLINOS (CSIC).

31 Acto I, línea 606 del TESO; pp. 57-8 del Tomo XV, Comedias novelescas, tercera sección de Obras por la RAE (1913).

32 Jornada 3.a , línea 211 del TESO; p. 491 del Tomo III (Nueva edición) de Obras dramáticas por la RAE (1917).

33 Jornada $2 .^{\text {a }}$, línea 760 del TESO; p. 428 del Tomo VI, Comedias mitológicas, comedias históricas de asunto extranjero de Obras por la RAE (1896). 
De Lucinda perseguida:

PRínCIPE.-El Conde viene; embózate, Rodulfo, / que si es verdad, el lobo está en el cuento. (Sale el Conde) ${ }^{34}$.

\title{
De Los locos de Valencia:
}

GERARDO.-En todo he de seguir vuestro consejo; mas esperad, que está en el cuento el lobo. / Verino.-_iDe qué manera es eso ? GERARDO.Beltrán viene ${ }^{35}$.

\section{De La francesilla:}

ROSARDO.-El viejo está en la fábula. Déjame, / que quiero dar un tiento a la fortuna./ LISENO.-Y yo, morir sin esperanza alguna ${ }^{36}$.

Y volvemos a Calderón, porque encontramos la frase romanceada en su comedia Bien vengas, mal, si vienes solo en un contexto típico de enredo donde el tiempo literario obra el milagro de la escena:

\begin{abstract}
ANA.-Pues no estás muy segura / aquí de que te vea, y tendrá queja. / INÉs.-Aunque es cosa muy vieja / decir cuando la voz ocasión toma, / esto del ruin de Roma / y el lobo en la conseja, / tu hermano en casa ha entrado. / MARÍA.-Escóndame este cuarto. ANA.-Está cerrado: / no entres en él. MARÍA.-Abierto está. / ANA.-Detente. / MARÍA.-Pues ¿sálesme al encuentro? / ANA.-Sí, porque es entrar dentro / mayor inconveniente / que verte aquí tu hermano. MARÍA.—¿Mayor inconveniente? ANA.-Sí, y es llano. / MARía.-Poco de mí confías. / ANA.-Es mucho lo que guardo. / MARÍA.-Ya en esconderme tardo. / ANA.-Pues en corto venías, / cúbrete con el manto; / que no ha de conocerte. / MARÍA.-iAy, cielo santo! / (Tápanse doña María y Juana, y retíranse). (Sale Don Luis) ${ }^{37}$.
\end{abstract}

El lobo en la conseja lo ha tomado Calderón de una obra que le atraía casi tanto como Don Quijote de la Mancha:

Areusa._¿Quién es? / Elicia._Ábreme, amiga; Elicia soy. / AreuSA.Entra, hermana mía. [...] . / Elicia.-A tu puerta llaman. Poco espacio nos dan para hablar, que te quería preguntar si avía venido acá Sosia. / AREUSA.-No ha venido; después hablaremos. ¡Qué porradas que dan! Quiero yr abrir, que o es loco o privado quien llama. / SosiA.-Ábreme,

34 Jornada 3. ${ }^{\text {, }}$ línea 722 del TESO; p. 357 del Tomo VII (Nueva edición) de Obras dramáticas por la RAE (1930).

35 Jornada 3. ${ }^{a}$, línea 67; p. 434 del Tomo XII (Nueva edición) de Obras dramáticas por la $R A E$ (1930).

${ }_{36}$ Jornada 3., p. 773 de Comedias, IV, de Lope de Vega. Madrid, Turner. Biblioteca Castro. 1993.

37 Jornada 2. ${ }^{\text {a }}$, p. 621 de Obras completas, II. Folios 495-96 de Novena Parte de Comedias. Madrid, 1698, conocerme (por conocerte en la edición de 1691). Y la acotación escénica: Tápanse Doña María y Juana; retíranse, y sale D. Luis. 
señora, Sosia soy, criado de Calisto. / AREUSA.-Por los sanctos de Dios, el lobo es en la conseja. Escóndete, hermana, tras esse paramento, [... ${ }^{38}$.

La frase que nos parece propia la registra el Diccionario de Autoridades V:

En nombrando al ruin de Roma luego assoma. Phrase que en estilo festivo se usa para decir ha llegado aquel de quien se estaba hablando. Lat. Lupus est in fabula.

Más moderna es hablando del rey de Roma, mira por donde aso$m a$, ya que se considera históricamente rey de Roma a Napoleón II (1811-1832). «Clarín» en La regenta la usa, y se dice en la actualidad.

Y en cuanto a la alusión "así Lope a sus fámulos lo dijo», fámulo 'criado', como derivado de familia, Calderón en este contexto creo que le quiere dar un significado espiritual distinto al de "criado', que sí está en la comedia El mariscal de Viron de Juan Pérez de Montalbán:

[Monsiur de] Laf[in].-El Duque viene, señor. / Xaq[ues, criado del Mariscal de Viron].—¿No es aquel mi amo? La[fin].—Sí. / Xaq[ues].—Pues Xaques, xaque de aquí, / que es necedad superior, / (aunque en la comedia vsada), / que estando hablando los amos, / nos los fámulos queramos / meter nuestra cucharada. (Vase Xaques y Lafin. Salen el Duque de Viron) ${ }^{39}$.

\section{RESUMEN}

En estas páginas hemos estudiado cómo Calderón, en algunas de las comedias donde cita personajes de la obra cervantina, escri-

38 Rojas, Fernando de: Comedia o Tragicomedia de Calisto y Melibea. Edición de Peter E. Rusell. Madrid, Clásicos Castalia. 1991, p. 544 (Auto XVII). Sin embargo el dicho latino está presente en tratados doctrinales escritos con rasgos populares, como son La lengua de Erasmo nuevamente romanceada por muy elegante estilo ( $\mathrm{Si}$ algunos hablan en secreto y viene el tal parlero, antes que llegue se van uno a uno; si acaso sobreviene de súbito, luego callan, diziendo lo que dize el refrán: el lobo está en la conseja»), de Bernardo Pérez de Chinchón (1533) y el Jardín de flores curiosas ( $« . .$. pero podré decir lupus est in fabula, porque si no me engaño, aquel que allí viene es Antonio») de Antonio de Torquemada (1570). E igualmente el maestro Correas (1627) registra varios ejemplos.

39 Jornada 3. ${ }^{\text {, }}$, folio $111 \mathrm{v}$. del Tomo Primero / de las / Comedias del Dotor / Ivan Pérez de Montalván / [...] / En Valencia / 1652; signatura T-6881 de la B.N. de Madrid, y folio 117 v. de la Parte Quarenta y tres / de / Comedias / de diferentes avtores / [...] / Caragoça / 1650, signatura U-10, 329 de la Biblioteca Nacional. Véase nota 1 a FAMILIA en el DCECH II de J. Corominas y J. A. Pascual. Madrid, Gredos, 1980, p. 846. 
be un léxico característico de los libros de caballerías. Así, por ejemplo, encontramos cómo los personajes (que en definitiva reflejan la sensibilidad del autor por definir ciertas palabras o términos que le parecen muy característicos en comedias y autos sacramentales) matizan qué es mudanza (en No hay burlas con el amor) y locura (en Manos blancas no ofenden).

Como referimos en el anterior trabajo, creemos que las citas de Lope de Vega son menos numerosas que las de Cervantes, si bien no falta la admiración. Y las hemos podido clasificar en tres apartados:

1) Las citas o alusiones normales (Los melindres de Belisa y El perro del hortelano, está basada en un dicho popular del tipo tercero).

2) «En mi pena se infiere / que el que piensa que no quiere, / el ser querido le engaña», poesía de Vega Carpio publicada sin firma en la Primavera y flor de los mejores romances (1621), que el dramaturgo desarrolló más tarde en comedia.

3) Lupus in fabula, dicho latino de gran fortuna en la Literatura española, que viene de las fuentes clásicas y que nos ha llevado a abocetar su presencia como frase hecha en romance en varios autores, y emparentado con el popular y más moderno «Hablando del rey de Roma, mira por donde asoma», que Calderón, magistral oído, recordó en "cuando la voz ocasión toma, / esto del ruin de Roma / y el lobo en la conseja» (véase tomo V del Dicc. de Autoridades).

JosÉ CARLOS DE TORRES

Instituto de Filología. CSIC 